\title{
O TALENTO NO FUTEBOL NA PERSPECTIVA DA BIBLIOGRAFIA BRASILEIRA ${ }^{66}$
}

\author{
Thaynara do Prado Szeremeta \\ Universidade Federal do Paraná, Curitiba, Paraná, Brasil \\ Carlos Eduardo de Barros Gonçalves \\ Universidade de Coimbra, Coimbra, Portugal \\ André Mendes Capraro \\ Universidade Federal do Paraná, Curitiba, Paraná, Brasil \\ Camile Luciane Silva \\ Universidade Federal do Paraná, Curitiba, Paraná, Brasil \\ Fernando Renato Cavichiolli \\ Universidade Federal do Paraná, Curitiba, Paraná, Brasil
}

\begin{abstract}
Resumo
A detecção, seleção e promoção de talentos esportivos se constitui como um processo de relevância tanto no âmbito bio-psico-social, quanto no âmbito econômico, visto o impacto que a identificação de atletas de alto nível traz a sociedade. Sendo assim, o presente trabalho teve como objetivo fazer um levantamento acerca da temática, utilizando como método a análise de conteúdo. O processo é visto por um duplo viés: a lógica mercadológica e humano-holística. Há indícios de prevalência da lógica mercadológica, em que a valorização se dá, essencialmente, pelos capitais futebolísticos, que, por sua vez, apresentam uma difícil reconversão em outros capitais.
\end{abstract}

Palavras-chaves: Aptidão. Futebol. Atletas.

\section{Introdução}

O esporte é um fenômeno que está presente no cotidiano. Nos meios de comunicação (SILVA, 2007), no bate-papo das pessoas, ou nas ações de governo (CASTRO et al., 2012; DONHA, 2013; STAREPRAVO; REIS; MEZZADRI, 2010; STAREPRAVO; SOUZA; MARCHI

\footnotetext{
${ }^{66}$ Esta pesquisa foi financiada pelo CNPQ
} 
JR, 2013). Nas últimas décadas se caracterizou como uma das manifestações humanas que mais tem se desenvolvido (MARCHI JR., 2004a, p. 50), principalmente no âmbito econômico.

Neste contexto, Bohme (1999) avalia a área de diagnóstico e prognóstico de talentos esportivos como um importante campo de atuação dos profissionais de educação física. É por meio desta área que novas gerações de atletas de alto nível são e serão detectados e treinados a longo prazo.

A predominância do termo talento esportivo, segundo Damo (2005), reflete a mudança no contexto do futebol e do esporte dos últimos anos, em que se destaca a importância dos profissionais da área no processo de lapidação e aperfeiçoamento do dom ${ }^{67}$ abandonando a ideia de que talento já "nasce pronto". Lanaro Filho e Bohme (2001) referem-se a "talento esportivo" como consequência da interação de características biológicas e psicológicas, influenciada pelo meio. Enquanto Bouchard e Lortie (1984) afirmam que o desenvolvimento do talento vai além dos componentes anatômicos e fisiológicos do indivíduo, ressaltando a determinação, decisão e um inflexível desejo de vencer.

Matsudo (1996) afirma que a falta de conhecimento e aceitação pelos técnicos esportivos sobre as pesquisas e metodologias desenvolvidas pelos teóricos são dificuldades encontradas na questão do talento esportivo.

Por muitas vezes, a identificação de um talento tem grande impacto no âmbito econômico. Podemos observar no futebol as vendas de jogadores como Neymar, que em 2013 teve uma rentabilidade de 500\% (PAMPLONA, 2013) enquanto o dólar, que foi a aplicação mais rentável do ano, teve um ganho de apenas 14,64\% (YAZBEK, 2013).

Para o presente trabalho será adotada a conceituação de Bohme (1999) que propõe a utilização de três termos referente à temática talento: detecção, seleção e promoção.

Detecção de talentos refere-se às medidas e meios utilizados para encontrar um número grande de indivíduos, dispostos a serem submetidos à formação esportiva básica. Seleção de talentos, por outro lado, é o meio utilizado para determinar os indivíduos que possuem condições de passar de um nível para o outro no treinamento que ocorre a longo prazo (BOHME, 2000); já promoção de talentos, é toda a medida objetiva que favorece o desenvolvimento de jovens talentosos para um determinado tipo de esporte e que proporciona um rendimento esportivo de alto nível (BOHME, $1999{ }^{68}$ apud MASSA et al., 2003).

67 “O dom é fundamentalmente, um termo que preenche um espaço que deveria ser ocupado por outro termo, um coringa, razão pela qual seu significado permanece oculto, em aberto (...)" (DAMO, 2005).

${ }^{68}$ BOHME, M. T. S. Aptidão física de jovens atletas do sexo feminino analisada em relação a determinados aspectos biológicos, idade cronológica e tipo de modalidade esportiva praticada. Tese (Livre Docência) — São Paulo: Universidade de São Paulo, 1999. 
Para fins didáticos, trabalharemos com os três termos separadamente, mas eles estão interrelacionados, sendo consequentemente dependentes uns dos outros, caracterizando o que Bohme (1995) chama de treinamento a longo prazo.

Nesse sentido, autores como Câmara (2009) e Monteiro (2011) afirmam que parte dos clubes ou escolinhas de futebol, utilizam de métodos empíricos para a detecção, seleção e promoção de atletas, deixando de lado os princípios teóricos. Antes do candidato iniciar a sua carreira, há indícios de uma pedagogia de exclusão, quando os mesmos são colocados à prova; isto é, a detecção do talento esportivo ocorre por métodos nitidamente empíricos. Quando o atleta é escolhido, passa a um processo de promoção duvidosa, muitas vezes defasado em relação à literatura atual. Há também que se destacar o fato que em muitos casos o "fator humano" é subjugado pelo modelo mercadológico. Isso pode gerar consequências sociais e psicológicas severas. Esse contexto instigou à problemática: quais são e o que dizem os trabalhos científicos que dão o suporte teórico para a temática detecção, seleção e promoção de talentos no futebol de campo? Assim foi realizada uma leitura sociológica do campo da produção sobre o tema, buscando identificar se existem indicativos de correntes teóricas e como o campo científico se posiciona acerca do empirismo presente no cotidiano futebolístico.

A lógica mercadológica leva a crer que no ambiente futebolístico há a predominância do pensamento analítico em que um "possível talento" é visto como um produto submetido à processos que cercam a valorização e circulação do seu dom sem pensar nas consequências sociais e psicológicas que o indivíduo possa adquirir. Nesse sentido, este trabalho adotou o modelo holístico referente a jogadores de futebol (RODRIGUES, 2003). O holismo, por sua vez, trata o homem como um ser indivisível, que não pode ser entendido através de uma análise separada de suas diferentes partes, além de implicar em premissas mais integrativas e orgânicas que retorna a visão da não separação ao integrar sensação, sentimento, razão e intuição. (GIULIANOTTI, 2002; GRINVALD, 1998; RODRIGUES, 2003). Portanto o objetivo é o de apresentar o estado da arte que permeia a temática detecção, seleção e promoção de talentos no futebol de campo, por meio de uma análise com viés sociológico.

\section{Metodologia}

O método de levantamento (construção) dos dados é caracterizado por Marconi e Lakatos (2003) como documentação indireta, tendo em vista a captação, leitura e análise de resumos e de trabalhos completos de teses e dissertações encontradas no Banco de Teses do Portal de Periódicos da Coordenação de Aperfeiçoamento de Pessoal de Nível Superior - Capes/MEC. Dessa forma, trata-se de um estudo sobre o estado da arte ou estado do conhecimento. Tomando-se a definição de Ferreira (2009), pode-se dizer que pesquisas como essas são entendidas como de caráter bibliográfico. Definiu-se esse banco de teses como fonte principal de informação, em virtude do mesmo permitir o acesso eletrônico à produção científica das pós-graduações do Brasil de forma atualizada. Por meio de uma ferramenta de busca e consulta, o banco passou a disponibilizar resumos de dissertações e teses para consulta a partir do ano de 1987 e os trabalhos completos desde 2004. A pesquisa pode ser realizada a partir do autor, do título, de palavras-chave, do nível (mestrado, doutorado e profissionalizante) e do ano base.

O recorte temporal desta pesquisa apresenta seu marco inicial no ano de 1987 em função de que este é o período em que o Banco de Teses do Portal da Capes, passa a fornecer os resumos de 
dissertações e teses, e seu término no ano de 2012. Assim, tem-se praticamente a produção na área em estudo no Brasil e as reflexões advindas da averiguação que são de importância vital ao demarcar as tendências atuais e estimular ideias futuras (fonte de pesquisa e informação) desse campo na Educação Física.

Para tratamento dos dados foi adotado a análise de conteúdo proposta por Bardin (1977) definida como uma técnica utilizada para fazer inferências através da identificação objetiva e sistemática de características específicas da mensagem.

Para Bardin (1977) a análise de conteúdo possui duas funções que podem ou não se dissociar quando colocadas em prática. A primeira função seria heurística, ou seja, enriquece a tentativa exploratória e aumenta a propensão à descoberta. Enquanto a outra função consiste na formulação de hipóteses. A autora elenca três fases fundamentais para a análise: a pré-análise, a exploração do material e o tratamento de dados.

A pré-análise consiste na organização de materiais a serem explorados e na leitura prévia dos mesmos. Embora ocorra a delimitação dos procedimentos nessa fase, deve haver certa flexibilidade do pesquisador, para dar abertura à formulação de hipóteses e argumentos a serem utilizados posteriormente. A exploração do material é o aprofundamento no corpus delimitado, a aplicação de hipóteses elaboradas na fase anterior e do referencial teórico. E o tratamento de dados é a análise propriamente dita. A reflexão, a intuição com embasamento em materiais empíricos estabelece relações com a realidade aprofundando as conexões das ideias (SILVA; GOBBI; SIMÃO, 2005).

A primeira etapa consistiu-se de uma busca no Banco de Teses do Portal da Capes com os seguintes descritores: detecção talentos, seleção talentos, promoção talentos, identificação talentos, talento futebol. A partir da leitura do resumo e palavras chaves com a premissa que abordassem exclusivamente a temática futebol, foram encontrados 21 teses e dissertações.

Como a plataforma de dados só fornece os resumos, se fez necessária a busca pelos trabalhos completos para leitura. Esta se deu primeiramente na biblioteca virtual da instituição de ensino do respectivo trabalho, e quando não encontrados, foi usado o mecanismo de pesquisa Google. Esse processo resultou em oito teses e dissertações para análise.

$\mathrm{Na}$ segunda etapa, foi realizada a leitura integral ou parcial dos trabalhos, determinada a partir da leitura prévia do sumário e da introdução, visto que, em alguns casos, apenas um capítulo se enquadrava na temática adotada. E por fim, foram analisados os materiais encontrados utilizando o conceito de capital proposto por Bourdieu.

O capital, no senso comum, carrega consigo sua significação econômica, sendo definido como bem ou produto de valor adquirido, acumulado. No entanto, a noção bourdiana extrapola seu significado além do econômico, se tratando de um conceito heurístico (SALVINI, 2012). Para Damo (2005) capital é "uma constelação de atributos que permitem a alguém inserir-se legitimamente num dado campo social". capital:

Conforme Nina, Caetano Jr e Assumpção (2009) é possível distinguir quatros tipos de

O capital econômico: constituído pelos fatores de produção e pelo conjunto de bens econômicos; o capital cultural: qualificações intelectuais produzidas pelo sistema escolar ou transmitidas pela família. Existe em três formas: em estado incorporado como disposição duradoura do corpo; em estado objetivo, como bem cultural; em estado institucionalizado; o capital social: conjunto das relações 
sociais de que dispõe um indivíduo ou grupo; o capital simbólico: conjunto dos rituais ligados à honra e ao reconhecimento.

Damo (2005) ainda acrescenta a noção de "capital futebolístico" que compreende as estratégias de conversão de dom em profissão, podendo elas ser abordadas em sentido amplo (referente a atributos que garantem o acesso do indivíduo a um centro de formação) e/ ou em sentido restrito (referente a atributos necessários propriamente corporais).

\section{Resultados}

Detecção de talentos no futebol

"A detecção e seleção de talentos se constituem como pilares de renovação e manutenção no futebol" (PAOLI p. 54, 2007). Mas o talento ainda carece de meios e métodos eficazes para sua promoção ser efetiva. O autor ainda afirma que não existe idade ideal para identificar um talento, porém a que mais se aproxima é entre 12 e 14 anos.

Os meios de detecção de talentos sofreram modificações no decorrer dos anos. Conforme Rodrigues (2003), antes da década de 1970 não havia qualquer utilização de procedimentos científicos, os talentos eram descobertos essencialmente nos campos de várzea. Com a modernização, a prática da modalidade nos campos de várzea se tornou cada vez mais inviável e de difícil acesso, a prática desinteressada passou a ser na rua (DAMO, 2005) enquanto as escolinhas, inicialmente, assumiram o papel de detectar talentos (RODRIGUES, 2003). No entanto, a procura por elas foi tanta que sua função primordial deixou de ser somente detectar talentos e passou a ser um mecanismo de atender a demanda de pais que almejavam a carreira de jogador para os filhos (DAMO, 2005). Assim, se fez necessário a invenção e utilização de outros dispositivos, como a indicação, peneiras e contratações (RODRIGUES, 2003) e o sistema de convênios e parcerias (PAOLI, 2007).

À luz da observação empírica e conforme a comunidade científica (CÂMARA, 2009; PAOLI, 2007; RODRIGUES, 2003) é notória as "peneiras" "69 na maioria dos clubes como destaque neste processo.

Quanto aos critérios utilizados para detecção, segundo Câmara (2009) a qualidade técnica seria primordial, seguida as qualidades táticas e, por fim, a qualidade física. O autor enfatiza ainda o passe como qualidade técnica e a velocidade como qualidade física. Paoli (2007) faz referência à presença das representações identitárias "futebol-arte" e "futebol-força" no processo de detecção de talentos, em que a arte se sobressai à força. Rodrigues (2003) enumera como critérios gerais a destreza, leitura do jogo, visão, interpretação, nível de potência, velocidade, estado emocional e combatividade.

Devido a especificidade de cada posição presente no futebol se torna inviável traçar um perfil genérico de talento, sendo necessário critérios específicos para cada posição (MONTEIRO,

69 "Peneira" é uma expressão popular que significa um processo de detecção empírico, em que os clubes avaliam um grande número de crianças e adolescentes, sendo a forma mais tradicional de captação de atletas para o futebol brasileiro (MONTAGNER e SILVA, 2003). 
2011; PAOLI, 2007). Monteiro (2011) aborda que não há nenhum critério citado simultaneamente em todas as posições, mas houve a predominância técnica em todas as posições, com ênfase ao "passe" e "drible/finta". Paoli (2007) concorda com a relevância dada a qualidade técnica e ainda acrescenta a importância de personalidade e velocidade em todas as posições.

Câmara (2009) e Cunha (2007) ressaltam a importância na diferenciação de talento com maturação precoce, uma vez que indivíduos pós púberes detêm maior vantagem em relação aos pré púberes, essencialmente relacionado ao desempenho físico. Confirma-se, assim, a importância de um processo pautado em métodos científicos e metodológicos não subjetivos (CÂMARA, 2009; CUNHA, 2007; MONTEIRO, 2011; PAOLI, 2007).

Outros indicadores invulgares também foram apontados como a posse de passaporte europeu (PALMIÉRI, 2009), capacidade de agregar capitais (DAMO, 2005), capacidade de adaptação e característica específica da região do atleta (PAOLI, 2007).

Monteiro (2011) preconiza a importância da integração no processo de detecção e seleção de talentos, visto que tal processo é um conjunto de variáveis que vai além de somente características inatas, predisposição genética ou influência do ambiente.

[...] No caso do futebol, é possível que as habilidades psicológicas perceptivas e cognitivas sejam indicadores melhores para predizer uma atuação destacada dos aspectos antropométricos, fisiológicos e, até mesmo, os aspectos motores, e de ordem técnica (REZENDE E VALDES, $2004^{70}$ apud MONTEIRO, p. 17, 2011).

Seleção de Talentos

Paoli (2007) afirma que o principal e mais utilizado critério de seleção é a idade cronológica sendo que o ideal seria pela idade biológica e capacidade apresentada pelo indivíduo até então. Ainda acrescenta que o processo de seleção é constante, ou seja, é necessário apresentar um bom desempenho na categoria sub 17 mesmo que este já tenha sido apresentado na categoria sub 15, por exemplo. Rodrigues (2003) aponta que os clubes têm deixado de lado o empirismo nesse processo, uma vez que a demanda é menor, se torna mais viável e segura a utilização de equipamentos científicos. Cunha (2007) ressalta a importância do controle da maturação biológica durante toda a fase de treinamento.

\section{Promoção de Talentos}

O termo "promoção" é incluído sobre o viés da formação do atleta, sendo assim, é enfatizado a necessidade de um processo de promoção para a eficácia da formação e consolidação como jogador de futebol (DAMO, 2005; PAOLI, 2007; PALMIERI, 2009; OLIVEIRA, 1988). Oliveira (1998) aponta o treinamento como forma de promoção, o qual é mais eficaz em idades mais avançadas, ou seja, entre 12 e 14 anos. Por outro lado, Palmiéri (2009) afirma que ocorre o

70 REZENDE, A; VALDES, H. Métodos de estudo das habilidades táticas 2: a abordagem tomada de decisão. Lecturas: Educación Física y Desportes, Buenos Aires, v. 69, p. 1-10. 2004. 
desenvolvimento do talento por meio do contato com os profissionais, ou seja, a promoção através do viés simbólico. O mesmo autor ainda coloca que o lugar onde o atleta foi formado e/ou atua, influencia a valorização do seu talento, uma vez que reflete os capitais futebolísticos adquiridos.

Quanto as condições necessárias para a promoção, Paoli (2007) aborda a unidade de trabalho entre as categorias, e ainda a estrutura administrativa, financeira e física. Na mesma direção, Palmieri (2009) e Rodrigues (2003) comparam a estrutura do clube a um laboratório científico, apontando que quanto melhor a estrutura, maior é a produção.

Nesse sentido, Damo (2005) aponta a diferença entre os termos "formação" e "produção". Enquanto formação reflete a valorização do atleta de forma mais humana, a produção remete ao atleta a um mero produto, seguindo a lógica do mercado. $\mathrm{O}$ autor aborda três modelos de formação: formação endógena (prioriza suprir a necessidade interna do clube), formação exógena (prioriza suprir a necessidade do mercado) e híbrida (também conhecida como oportunista, busca suprir a necessidade do clube e do mercado). O processo de promoção por meio do modelo endógeno prioriza treino enquanto o modelo exógeno prioriza visibilidade.

Os clubes brasileiros adotam predominantemente, o modelo híbrido, justificando-se assim a ênfase ao talento momentâneo. Palmieri (2009) aponta como atual vocação do futebol brasileiro exportar jogadores. Nesse cenário entra o papel do empresário, que tem se consolidado no mercado, inclusive perante a FIFA (DAMO, 2005; PAOLI, 2007; PALMIÉRI, 2009). Os empresários não medem esforços para promover os talentos futebolísticos, ultrapassando, muitas vezes, as barreiras da profissão, tornando-se amigo, psicólogo, ou ainda, "técnico fora de campo" (PALMIERI, 2009, p. 98). Vale a ressalta, que todo o processo de formação, enquanto promoção é incerto, uma vez que o "produto" é o ser humano (DAMO, 2005). 
DOI 10.5216/rpp.v18i2.33135

\begin{tabular}{|c|c|c|c|c|}
\hline Autor, Ano & Título & Detecção & Seleção & Promoção \\
\hline (OLIVEIRA, 1998) & $\begin{array}{l}\text { Hábitos de vida, motivação e aptidão física. Estudo em } \\
\text { Crianças e Jovens de } 10 \text { a } 14 \text { anos da Escolinha de Futebol } \\
\text { do Grêmio Foot-Ball Porto Alegrense. }\end{array}$ & . & 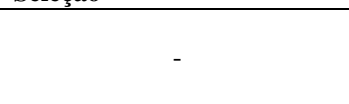 & $\begin{array}{l}\text { Consolidação do treinamento em } \\
\text { idade mais avançada (12 a } 14 \text { anos). }\end{array}$ \\
\hline $\begin{array}{l}\text { (RODRIGUES, } \\
\text { 2003) }\end{array}$ & $\begin{array}{l}\text { A formação do jogador de futebol no Sport Club } \\
\text { Internacional (1997-2002). }\end{array}$ & $\begin{array}{l}\text { Dispositivos de deteçãa de talentos: indicação, peneiras e } \\
\text { contratações. Critérios gerais utilizados: destreza, leitura de } \\
\text { jogo, visão, interpretação, nível de potência, velocidade, estado } \\
\text { emocional e combatividade. }\end{array}$ & $\begin{array}{l}\text { Utilização de equipamentos } \\
\text { científicos é mais viável e } \\
\text { segura, visto a demanda } \\
\text { menor. }\end{array}$ & $\begin{array}{l}\text { Comparação estrutura do clube a } \\
\text { um laboratório científico. }\end{array}$ \\
\hline (DAMO, 2005) & $\begin{array}{l}\text { Do dom à profissão. Uma etnografia do futebol de } \\
\text { espetáculo a partir da formação de jogadores no Brasil e na } \\
\text { França. }\end{array}$ & $\begin{array}{l}\text { Substituição dos campos de várzea pelas escolinhas. Relevância } \\
\text { da capacidade de agregar capitais. }\end{array}$ & - & $\begin{array}{l}\text { Diferença entre "formação" e } \\
\text { "produção". Modelos de formação: } \\
\text { endógena, exógena e híbrida. Papel } \\
\text { do empresário. }\end{array}$ \\
\hline (CUNHA, 2007) & $\begin{array}{l}\text { Efeito da maturação biológica sobre o consumo máximo de } \\
\text { oxigênio e limiares ventilatórios de jogadores de futebol. }\end{array}$ & Importância de avaliação da maturação biológica. & $\begin{array}{l}\text { Importância da avaliação da } \\
\text { maturação biológica. }\end{array}$ & - \\
\hline (PAOLI, 2007) & $\begin{array}{l}\text { Os estilos de futebol e os processos de seleção e detecção } \\
\text { de talentos. }\end{array}$ & $\begin{array}{l}\text { Dispositivos de detecção: indicação, peneiras, contratações, } \\
\text { sistemas de convênios e parcerias; Representações identitárias } \\
\text { presentes: "futebol arte" x "futebol força"; Necessidade de } \\
\text { critérios específicos para cada posição. }\end{array}$ & 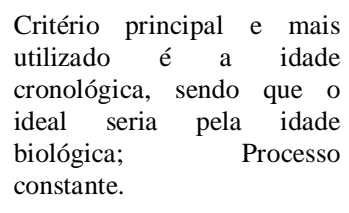 & $\begin{array}{l}\text { Condições necessárias: unidade de } \\
\text { trabalho e estrutura administrativa, } \\
\text { financeira e física; Papel do } \\
\text { empresário. }\end{array}$ \\
\hline (PALMIÉRI, 2009) & $\begin{array}{l}\text { Quanto vale um talento? Uma análise antropológica sobre a } \\
\text { valorização e circulação dos jogadores de futebol no } \\
\text { mercado esportivo. }\end{array}$ & A relevância de posse de passaporte europeu. & - & $\begin{array}{l}\text { Através do viés simbólico; } \\
\text { Valorização do lugar de formação } \\
\text { do atleta; Papel do empresário. }\end{array}$ \\
\hline (CÂMARA, 2009) & $\begin{array}{l}\text { Critérios comportamentais utilizados por técnicos na } \\
\text { avaliação do desempenho esportivo. }\end{array}$ & $\begin{array}{l}\text { Critérios utilizados: qualidade técnica, seguido das qualidades } \\
\text { táticas e qualidade física; Importância de avaliação da } \\
\text { maturação biológica. }\end{array}$ & - & - \\
\hline (MONTEIRO, 2011) & $\begin{array}{lllll}\text { Critérios de avaliação } & \text { utilizados por "olheiros" } & \text { e } \\
\text { observadores na seleção } & \text { de talentos esportivos para } & \text { o } \\
\text { futebol no Brasil. } & & & & \end{array}$ & Necessidade de critérios específicos para cada posição. & - & - \\
\hline Quadro1: & pesquisadas & contribuições & para & termos \\
\hline
\end{tabular}

Pensar a Prática, Goiânia, v. 18, n. 2, abr./jun. 2015 


\section{Discussão}

Quanto ao processo de detecção, seleção e promoção de talentos, apenas dois trabalhos abordam os três termos enquanto a maioria trata apenas do primeiro (detecção). Embora a maioria dos autores não abordem os três termos, é reducionista pensar em apenas um deles, visto que um influencia e acontece em decorrência do outro.

Em específico a detecção do talento esportivo, se antes era realizada somente na várzea, hoje há os processos de indicação, "peneiras", contratações além do sistema de convênio e parcerias. Esta transformação resultou somente na ampliação de seus meios em detrimento do descenso dos campos de "várzea", ou houve também um processo de incorporação de cientificidade e especificidade nesses meios? Nossos achados se concentram na concordância de alguns autores de que a detecção deve ser feita com base nas especificidades em que cada jogador desempenha em campo (posições), justificando a diversidade presente dentro de campo, assim alguns critérios são apontados como velocidade, habilidades táticas e técnicas, com ênfase para o passe, drible e finta. Monteiro (2011) ainda cita os critérios presentes na literatura para cada posição e afirma que há aproximação dos mesmos com a prática. Vale a ressalta de que, com a exceção dos atacantes, não há uma preocupação com as qualidades psicológicas, fato que deveria ser primordial, levando em consideração que pode favorecer ou desfavorecer o rendimento do jogador e até mesmo da equipe. Além dos aspectos psicológicos, os aspectos cognitivos, de certa forma, também são esquecidos. Ou seja, a forma como os autores expõem esses critérios, dão o entendimento de que mais vale um menino veloz e/ou habilidoso, do que aquele que sabe a ler jogadas ou sabe trabalhar sob pressão, por exemplo; o que é contrário ao entendimento do talento de forma global.

Então é possível, por meio de uma revisão de literatura, identificar quais são as características necessárias para o talento futebolístico. No entanto, definir qual método e como identificar esses atributos na prática se consolida como uma grande dificuldade no cenário atual. Em nossos achados não encontramos nenhuma indicação de como proceder quanto a isso. Mesmo sem estar relatados no corpus delimitado, existem instrumentos e procedimentos específicos para avaliar determinadas características. Pode-se citar o teste de velocidade Sprint $30 \mathrm{~m}$ (S30) que consiste na realização de dois sprints máximos em uma distância de 30 metros (OLIVEIRA et al., 2012), mensurando o tempo percorrido através de cronômetro (MARQUES; TRAVASSOS; ALMEIDA, 2010) ou fotocélulas (COELHO et al., 2011; OLIVEIRA et al., 2012), selecionando o melhor resultado entre as duas tentativas. Ainda se pode citar o teste para avaliar a habilidade especifica do drible: Drible Test (DT) (MARQUES; TRAVASSOS; ALMEIDA, 2010) que consiste em driblar ao redor de quatro cones, reproduzindo a figura de um oito, o mais rápido possível, podendo utilizar a mesma mensuração do S30.

Foram encontrados outros critérios incomuns, como a posse de passaporte europeu, que funcionaria como um "coringa", ou seja, um diferencial que permitiria escolher frente a indivíduos com características muito próximas, levando em consideração que alguns países limitam o número de extracomunitários por clube. Como a Europa é considerada a "Meca do futebol" (DAMO, 2005), quem já possui o passaporte, simplifica e facilita tanto os interesses próprios bem como de seu empresário e/ou clube interessado. Além disso, encontramos sobre a capacidade de agregar capitais, aqui se inclui, basicamente, a diferença entre o jogador "pronto" e o jogador com potencial. E ainda a capacidade de adaptação e a característica específica da região do atleta, ou seja, determinados traços e ações interiorizados que 
funcionam como princípio norteador. Ora, isso é relatado na teoria, mas é raro na prática, visto que, muitos observadores desconsideram esta capacidade de agregar capitais e de adaptação, em função do imediatismo, da necessidade de se encontrar um talento "para já". É ignorado, muitas vezes, que se o indivíduo não apresenta determinados atributos, talvez não esteja maturado biologicamente para tal, assim ocorre o declínio de um "talento em construção" em função de um "aparente talento pronto".

Se de um lado a detecção de talentos abrange um grande percentual dos trabalhos estudados, no que diz respeito à seleção, isso se restringe a poucos parágrafos. Dessa forma, entende-se que o campo intelectual reflete a prática, em que se estuda e se investe apenas na primeira etapa de formação de um talento, não há continuidade, e assim, cai-se no subjetivismo, ou recorre-se a um único e simples critério: idade biológica. Não há registro em nossos achados de testes, diversificação de critérios e até mesmo de cientificidade, por mínima e simples que seja para saber se realmente o jogador tem condições de avançar a níveis mais altos de rendimento. Ainda desconsidera-se, muitas vezes, a idade biológica, levando em consideração possíveis atrasos biológicos, muitos talentos são desperdiçados por apenas estarem "atrasados" no processo (MALINA et al , 2000; MALINA e BOUCHARD, 2001; MIRWALD et al, 2002; MAZZUCO, 2007). Por outro lado, é destacado que o fato de o garoto pertencer ao clube não é considerado critério de seleção. Esta condição funciona como um estímulo para o atleta. No entanto, há a desvalorização do considerado "prata da casa", em que, se o mesmo não apresenta o desempenho esperado, seja físico, técnico, psicológico e até mesmo social, pode vir a ser descartado pelo clube. É mais "cômodo" para o clube buscar jogadores que já tenham adquiridos os capitais esperados para determinada categoria, do que desenvolver e aplicar métodos para os seus jogadores, que talvez tenham uma grande capacidade para agregá-los, mas que se perde em um meio não qualificado para tal, resultando, novamente, em desperdício de um possível talento (CÂMARA, 2009).

A promoção é extremamente necessária para a eficácia dos processos mencionados anteriormente. Não tem sentido detectar e selecionar talentos, se não houver meios e métodos preocupados em promovê-los. Nesse contexto, encontramos a promoção realizada pelo viés simbólico, em que consiste basicamente no contato da base com os profissionais. É interessante para o menino que "sonha" com o profissionalismo, ter proximidade e facilidade de acesso com quem já trilhou o mesmo caminho que ele.

Outro fator de destaque é o treinamento como forma de promoção. Este deve possibilitar ao jogador condições suficientes de desenvolver e aplicar os capitais futebolísticos apresentados até então, deve respeitar a individualidade de cada jogador, estimulando-o ao trabalho em grupo e ao mesmo tempo fazê-lo descobrir o seu papel e importância individual no time. Um treinamento eficaz extrapola indo além da técnica, é aquele que possibilita ao atleta desenvolver valores e princípios que se aplicam além do campo. Com o sentido de valorizar a formação humano-holística, clubes como o Ajax da Holanda e o Internacional de Porto Alegre desempenharam propostas com uma perspectiva mais global, tendo como objetivo principal a incorporação de capitais que não sejam exclusivamente os futebolísticos, como valores educacionais (parcerias com escolas particulares) e culturais (investimento em cursos de inglês). Assim, tem-se uma formação qualificada não de "mercadorias" do universo futebolístico, mas sim de atletas, seres humanos, com valores e princípios estabelecidos para o mundo fora do futebol.

Já no lado mercadológico, destaca-se a figura do agente e/ou empresário, que atua principalmente na fase de promoção do talento. Responsável pela visibilidade do seu atleta no "mercado da bola", ele utiliza de vários meios e métodos a fim de exercer sua função. Desta 
forma é inegável que para o empresário obter sucesso é necessário ser portador de um grande volume de capitais. Assim, pode-se citar o capital econômico, a fim de subsidiar o atleta em possíveis necessidades financeiras; o capital social, visto que as relações sociais constituem peças fundamentais nas circulações e troca de informações a qual o futebol é dependente; e ainda o capital simbólico, que se configura como peça principal para conseguir o melhor contrato, no melhor clube ou agenciar o melhor talento.

O empresário hoje se constitui como um agente importante, tanto para clubes, como para os futuros jogadores. Se por um lado o trabalho dele absorve parte do lucro dos jogadores e dos clubes, por outro, ele detém os capitais necessários para estabelecer comunicação entre o clube e o jogador, e entre o jogador e o mercado. No entanto, mesmo com regulamentação da profissão pela FIFA, a falta de regulamentação legal para atletas menores de 16 anos, dificulta, de certo modo, as relações entre os indivíduos envolvidos no investimento e mercantilização do talento.

\title{
Considerações Finais
}

Não é possível pensar um talento futebolístico sem voltar o olhar para os processos de detecção, seleção e promoção de forma integrada. São poucos os trabalhos que abordam os três termos, dando ênfase à detecção e deixando em segundo plano a seleção e promoção.

Os critérios para a detecção que mais se destacaram foram velocidade e técnica (ênfase para o passe), os principais meios são as "peneiras", escolinhas e o sistema de convênios e parcerias. No entanto, há ausência de procedimentos científicos para identificar os critérios apontados, prevalecendo o empirismo e subjetivismo. Já na seleção o único critério encontrado diz respeito à idade biológica. Acredita-se haver outros critérios, porém não foram relatados nos estudos selecionados. Enquanto na promoção há ênfase na importância do treinamento, infraestrutura do clube e bons profissionais, além da relevância da promoção pelo viés simbólico.

O empresário se configura como um agente do mundo esportivo, que estabelece relações entre mercado, atletas e clube. Há indícios da prevalência da lógica mercadológica em todo esse processo, enfatizando-se apenas os capitais futebolísticos, que por sua vez, apresenta uma difícil reconversão em outros capitais. Esquecendo, assim, a importância da formação integral do indivíduo.

Por se tratar de uma investigação somente sobre teses e dissertações, é sugestivo expandir a pesquisa para artigos presente em algumas bases de dados nacionais e internacionais.

\section{THE TALENT IN SOCCER BY THE BRAZILIAN BIBLIOGRAPHIC PERSPECTIVE}

\begin{abstract}
Detection, selection and promotion of sports talents have an important role in the economical context as well as in the bio-psycho-social context. Thereby, the aim of the present study was to review the literature about this theme using the content analysis method. The process have a double interpretation: the market logic and the human-holistic logic. There are evidence about the prevalence of the market logic, in which the appreciation occurs, essentially, by soccer-related capitals, which hardly will be converted into other kinds of capital.
\end{abstract}

Keywords: Aptitude. Soccer. Athletes. 


\section{TALENTO EN FÚTBOL EN VISTA DE LA LITERATURA BRASILEÑA}

\section{Resumen}

La detección, selección y promoción del talento deportivo, se convierte en un proceso de importancia, tanto en el contexto bio-psico-social, así como en el contexto económico, como el impacto que la identificación de los deportistas de alto nivel aporta la sociedad. Por lo tanto, este estudio tuvo como objetivo revisar la literatura sobre el tema: la detección, selección y promoción del talento en el campo de fútbol de Brasil, usando como método análisis de contenido. El proceso se ve en un doble sesgo: la lógica del mercado y la lógica humana integral. Hay evidencia de que la prevalencia de la lógica del mercado, donde se produce la valoración, esencialmente por la capital del fútbol, que, a su vez, presenta una conversión difícil de otras capitales.

Palabras-clave: Aptitude. Fútbol. Atletas.

\section{Referências}

BARDIN, L. Análise de Contéudo. Edições 70 ed. Lisboa.1977

BOHME, M. T. S. Talento esportivo II: Determinação de talentos esportivos. Revista Paulista de Educação Física, v. 9, n. 2, p. 138-146, 1995.

BOHME, M. T. S. Aptidão física de jovens atletas do sexo feminino analisada em relação a determinados aspectos biológicos, idade cronológica e tipo de modalidade esportiva praticada. Tese (Livre Docência) — USP, São Paulo, 1999.

OHME, M. T. S. O treinamento a longo prazo e o processo de detecção, seleção e promoção de talentos esportivos. Revista Brasileira de Ciências do Esporte, Campinas, v. 21, n. 2/3, p. 4-10, jan./maio., 2000.

BOUCHARD, C.; LORTIE, G. Heredity and endurance performance. Sports Medicine, v. 1, n. 1, p. 38-64, 1984.

BOURDIEU, P. Algumas propriedades dos campos. In: Questões de sociologia. Rio de Janeiro: Marco Zero,1983. p. 94.

CÂMARA, H. C. R. Critérios comportamentais utilizados por técnicos na avaliação do desempenho esportivo de futebolistas das categorias de base. Dissertação (Mestrado em Psicologia) — UFRN,Natal, 2009.

CASTRO, S. B. E. et al. O estado da arte em políticas sociais de esporte e lazer no Brasil (2000-2009). Pensar a Prática, [s.1.], v. 15, n. 2, p. 531-545, jun., 2012.

COELHO, D. B. et al. Correlação entre o desempenho de jogadores de futebol no teste de sprint de 30m e no teste de salto vertical. Motriz, Rio Claro, v. 17, n. 1, p. 63-70, jan./mar., 2011.

CUNHA, G. DOS S. Efeito da maturação biológica sobre o consumo máximo de oxigênio e limiares ventilatórios de jogadores de futebol. Dissertação (Mestrado em Ciências do Movimento Humano) — UFRGS, Porto Alegre, 2007. 
DAMO, A. S. Do dom à proffisão: uma etnografia do futebol espetáculo a partir da formação de jogadores no brasil e na frança. Tese (Doutorado em Antropologia Social) UFRGS, Porto Alegre, 2005.

DONHA, E. L. Financiamente público-privado na copa do mundo de futebol no Brasil: O caso do estádio Joaquim Américo. Dissertação (Mestrado em Educação Física) — UFPR, Curitiba, 2013.

FERREIRA, A. L. P. F. O estado da arte da sociologia do esporte no Brasil: Um mapeamento da produção bibliográfica de 1997 a 2007. Dissertação (Mestrado em Sociologia) - UFPR, Curitiba, 2009.

GIULIANOTTI, R. Sociologia do futebol: dimensões históricas e socioculturais do esporte das multidões. São Paulo, Nova Alexandria: 2002.

GRINVALD, R. C. Futbol: deteccióny desarollo del talento desportivo. Lecturas: Educación Física e Desportes, revista digital, v. 10, n. 3, 1998.

LANARO FILHO, P.; BOHME, M. T. S. Detecção, seleção e promoção de talentos esportivos em ginástica rítima desportiva: Um estudo de revisão. Revista Paulista de Educação Física, São Paulo, v. 15, n. 2, p. 154-168, jul./dez., 2001.

MALINA, R. M. et al. Height, mass and skeletal maturity of elite Portuguese soccer players aged 11-16 years. Journal of Sports Sciences, v. 18, p. 685-93, sep, 2000.

MALINA, R. M.; BOUCHARD, C. Atividade Física do atleta jovem: do crescimento à maturação. Roca ed. São Paulo. 2001.

MARCHI JR, W. "Sacando" o voleibol: do amadorismo à espetacularizaçao da modalidade no Brasil (1970-2000). Tese (Doutorado em Educação Física) Unicamp,Campinas, 2001.

MARCONI, M. DE A.; LAKATOS, E. M. Fundamentos de Metodologia Científica. 5. ed. São Paulo: Atlas, 2003.

MARQUES, M. C.; TRAVASSOS, B.; ALMEIDA, R. A força explosiva, velocidade e capacidades motoras específicas em futebolistas juniores amadores $\square$ : Um estudo correlacional. Motricidade,Vila Real, v. 6, n. 3, p. 5-12, set., 2010.

MASSA, M. et al. Análise de referenciais cineantropométricos de atletas de voleibol masculino envolvidos em processos de promoção de talentos. Revista Mackenzie de Educação Física e Esporte, Barueri, v. 2, n. 2, p. 101-113, 2003.

MATSUDO, V. K. R. Prediction of Future Athletic Excellence. In: Bar-Or O. (organizador). The child and adolescent athlete.Oxford: Blackwell Science (The Encyclopaedia of Sports Science), p. 92-109, 1996.

MAZZUCO, M. A. Relação entre maturação, variáveis antropométricas, fisiológicas e motoras em atletas de futebol de 12 a 16 anos. Dissertação (Mestrado em Educação Física)-UFPR,Curitiba, 2007. 
MIRWALD, R. L. et al. An assessment of maturity from anthropometric measurements. Medicine \& Sciense of Sports \& Exercise, v. 34, n. 4, p. 689-694, 2002.

MONTAGNER, P. C.; SILVA, C. C. O. Reflexões acerca do treinamento a longo prazo e a seleção de talentos através de "peneiras" no futebol. Revista Brasileira de Ciência e Esporte, Campinas, v. 24, n. 2, p. 187-200, jan., 2003.

MONTEIRO, L. C. Critérios de avaliação utilizados por "olheiros" e observadores na seleção de talentos esportivos para o futebol no brasil. Dissertação (Mestrado em Educação Física) — UnB, Brasília, 2011.

NINA, A.; CAETANO JR, M. A.; ASSUMPÇÃO, L. O. T. Educaçao Física, Socialização , Capital e Campo. Educação Física em Revista, v. 3, n. 3, set./dez., 2009.

OLIVEIRA, J. L. N. HÁBITOS DE VIDA, MOTIVAÇÃO E APTIDÃO FÍSICA. Estudo em Crianças e Jovens de 10 a 14 anos da Escolinha de Futebol do Grêmio Foot-Ball Porto Alegrense. Dissertação (Mestrado em Ciências do Movimento Humano) - UFRGS, Porto Alegre, 1998.

OLIVEIRA, R. S. et al. Relação entre variabilidade da frequência cardíaca e aumento no desempenho físico em jogadores de futebol. Revista Brasileira de Cineantropometria e Desempenho Humano, v. 14, n. 6, 16 nov. 2012.

PALMIÉRI, J. C. J. Quanto vale um talento?uma análise antropológica sobre a valorização e circulação dos jogadores de futebol no mercado esportivo. Dissertação (Mestrado em Antropologia Social) — UFSCAR,São Carlos,2009.

PAMPLONA, N. Investir em craques defutebol vira mina de ouro. Disponível em: <brasileconomico.ig.com.br/noticias/investir-em-craques-do-futebol-vira-mina-deouro 132535.html>. Acesso em 15 de fevereiro de 2014

PAOLI, P. B. Os estilos de futebol e os processos de seleção e detecção de talentos. Tese (Doutorado em Educação Física) — UGF,Rio de Janeiro, 2007.

RODRIGUES, F. X. F. A formação do jogador de futebol no sport club internacional (1997-2002). Dissertação (Mestrado em Sociologia) — UFRGS,Porto Alegre, 2003.

SALVINI, L. Novo mundo futebol clube e o "velho" mundo do futebol: considerações sociológicas sobre o habitus esportivo de jogadoras de futebol. Dissertação (Mestrado em Educação Física) — UFPR, Curitiba, 2012.

SILVA, C. L. PRODUÇÃO TELEVISIVA ESPORTIVA $\square$ : Um estudo das ações e disposições dos agentes midiáticos a partir do programa Globo Esporte ( regional / Paraná ). Dissertação (Mestrado em Educação Física) — UFPR, Curitiba, 2007.

SILVA, C. R.; GOBBI, B. C.; SIMÃO, A. A. Uso da análise de conteudo como uma ferramenta para a pesquisa qualitativa: descrição e aplicação do método. Organizações Rurais e Agroindustriais, v. 7, n. 1, p. 70-81, 2005. 
STAREPRAVO, F. A.; REIS, L. J. DE A.; MEZZADRI, F. M. Esporte universitário brasileiro:uma leitura a partir de suas relaçoes com o estado. Revista Brasileira de Ciência e Esporte, Campinas, v. 31, n. 3, p. 131-148, maio, 2010.

STAREPRAVO, F. A.; SOUZA, J. DE; MARCHI JR, W. Políticas públicas de esporte e lazer no Brasil: Uma argumentação inicial sobre a importância da utilização da teoria dos campos de Pierre Bourdieu. Revista Brasileira de Ciência e Esporte, Porto Alegre, v. 35, n. 3, p. 785-798, set., 2013.

WACQUANT, L. Esclarecer o Habitus. Educaçao \& Linguagem, v. 16, n. 10, p. 63-71, 2007.

YAZBEK, P. Os melhores e os piores investimentos de 2013. Disponível em: $<$ http://exame.abril.com.br/seu-dinheiro/noticias/os-melhores-e-os-piores-investimentos-de2013 >. Acesso em 12 de maio de 2014.

Recebido em: 05/12/2014

Revisado em: 13/05/2015

Aprovado em: 10/06/2015

Endereço para correspondência:

André Mendes Capraro

andrecapraro@onda.com.br

Universidade Federal do Paraná, Departamento de Educação Física.

Rua Coração de Maria, 92 - BR 116 km 95

Campo Comprido

80215-370 - Curitiba, PR - Brasil 